\title{
Major Cytogenetic Response in Chronic Myelogenous Leukemia, BCR-ABL1 Positive
}

National Cancer Institute

\section{Source}

National Cancer Institute. Major Cytogenetic Response in Chronic Myelogenous

Leukemia, BCR-ABL1 Positive. NCI Thesaurus. Code C129529.

A cytogenetic finding indicating Philadelphia chromosome positivity less than or equal to $35 \%$ in a patient treated for chronic myelogenous leukemia, BCR-ABL1 positive. 